\title{
A Comparative Study of Identity Styles, Quality of Life and Behavioral Problems between Single Parent and Two Parent Adolescents
}

\author{
Abedini, Zoleykha ${ }^{1}$, Mirnasab, Mirmahmoud ${ }^{1} \&$ Fathi Azar, Eskander $^{1}$ \\ ${ }^{1}$ Department of Education, Faculty of Education and Psychology, University of Tabriz, Tabriz, Iran \\ Correspondence: Abedini, Zoleykha, Department of Education, Faculty of Education and Psychology, University \\ of Tabriz, Tabriz, Iran. E-mail: z.abedini20@yahoo.com
}

Received: December 15, 2016

Accepted: January 18, 2017 Online Published: February 13, 2017

doi:10.5539/jel.v6n2p235

URL: http://doi.org/10.5539/jel.v6n2p235

\begin{abstract}
The present study aimed to investigate identity styles, quality of life and behavioral difficulties between adolescents with single and two-parent status. In this causal- comparative study, a total of 214 high school students were selected, then 112 single parent students (59 females and 53 males) were selected by the voluntary response sampling method. Also, 112 students with two parent status were randomly selected. Identity styles Inventory (Bennion \& Adams, 1986), quality of life questionnaire and Achenbach Youth Self-Report (YSR) were administered. Analysis of variance and t-test for independent groups were used for analyzing the data. The results showed that in terms of moratorium and Identity diffusion there is no significant difference between single parent and two parent adolescents but there was significant difference in terms of Identity achieved and foreclosure. Single parent adolescents had more Identity achieved and two parent adolescents had more foreclosure. Additionally, the comparisons of quality of life components between these two groups showed that the groups had no significant difference in any of the following measures of the quality of life (e.g., physical health, psychological, social relationships and environmental domains). Finally, the findings showed that there was significant difference between the two groups in terms of behavioral problems. The study showed that single parent adolescents are more anxious/depressive than their two parent peers. This research has some implications for the future studies on investigating the role of family structure in adolescents' psychological status.
\end{abstract}

Keywords: adolescent, behavioral difficulties, identity styles, quality of life, single parent and two parent

\section{Introduction}

Family as the smallest unit of society has always attracted the attention of researchers. Family is defined by the United States Census Bureau as "two or more people who are in a household by birth, marriage or adoption or living together" (Gladding, 2011). However, due to several factors affecting its structure, we are sometimes faced with single-parent families. Single-parent families refer to those whose father or mother is absent for reasons such as divorce, marital separation, out-of-wedlock pregnancy, death (Greenberg, 2002), leaving the house, imprisonment, adoption and uncontrollable circumstances such as deployment to war zones (Gladding, 2011). Many single-parent children have emerged due to the increased number of single-parent families caused by divorce or marital separation - a growing phenomenon in Iranian society in recent years (Note 1) (Jiumpanyarach, 2011). Single-parent status affects their mental, emotional and psychological status (Singh \& Kiran, 2012) thus in response to many changes, they may be more irritable or cranky or react with disobedience and other behaviors affected by peers, siblings or adults (Hargreaves, 1991; quoted from Landucci, 2008). According to the findings of Samuelson (1997), the single-parent adolescents who are mostly present in society are more vulnerable than the single-parent children and young children who have not yet entered the community. Adolescence refers to the span of years over which individuals make the transition from childhood to adulthood (Santrak, 2003) and their identity is formed. Accordingly, the effects of upbringing (education) on the formation of identity in single-parent families seem to be significant in adolescence.

Identity, according to James Marcia, is an internal, self-constructed, dynamic structure of attitudes, drives, abilities, beliefs, and individual history. Researchers assess identity formation progress, using the clinical method developed by James Marcia or short questionnaires, on the basis of two criteria derived from Erikson's theory: 
exploration and commitment. The combination of different levels of exploration and commitment yield four identity statuses: identity achievement, identity diffusion, foreclosure and moratorium (Marcia, 1966). Identity development is always affected by many factors constantly interacting with the physical and social world (e.g., gender, age, religion, social status, cultural factors and social factors). Among the social factors, family and friends have the greatest impact on the person's identity (Para, 2008). Škraban (2008) showed the important role the presence of both parents and their psychosocial development play in identity development for female children. It is important to note that single-parent adolescents experience identity crisis earlier and longer than those in intact families (Vaičiuliene, 1999). Slutsky et al. (2016) found that the quality of parent-child relationship has a significant impact on identity development in adolescents who experience the absence of their father. Parent-adolescent relationship is associated with identity formation process in a way that a relationship can be assumed between parental coalition and the two statuses of moratorium and identity diffusion (Faber, Edwards, Bauer, \& Wetcher, 2006), while Imbimbo (1995) reported no significant difference between adolescents in divorced and normal (intact) families in terms of identity styles. These apparently contradictory findings suggest a significant research gap. Burt and Paysnick (2014) also reported a negative relationship between identity, stress and behavioral and emotional problems, while Schwatz and Pantin (2005) showed the indirect effect of behavior problems on identity.

In addition to identity styles, it seems that, adolescents in single-parent and two-parent families are different in terms of behavioral problems. Behavioral problem is a situation in which the child's behavioral reactions are in contrast to cultural, ethnic and age norms and negatively impact the individual's performance on education, social relationships, adjustment, behavior in the classroom and environmental adaptation (Gobari-Bonab, Parand, Khanzade Firoozjah, Movaleli, \& Nemati, 2008). Parents play a significant role in the emergence of behavioral problems, due to factors such as acceptance, marital adjustment, discipline, protection, neglect, indulgence, utopian expectations, realism, lenient standards, carelessness, moralism, freedom, and faulty role expectations (Mishra \& Kiran, 2013), the reason is that family and home play important roles in the growth of children (Ahiaoma, 2013). Karimi, Bolgari and Asgharnejad (2007) reported that children experiencing absence of the father will show more behavioral problems than children in normal families. Children of divorce, according to Liu et al. (2000), are characterized by aggressive behavior, withdrawal, and social problem. Seifollah Poor-Bonab and Keshavarzi-Arshadi (2015) found significant differences between the girls of single-parent and two-parent families in the two subscales of somatic complaints and conduct disorder. As reported by Usakli (2013), single-parent children were less daring and more submissive and aggressive than two-parent children. Slobodskaya (2015) found that behavioral problems are indirectly affected by family structure through parental behaviors, family interactions and socioeconomic factors. Ryan, Claessens and Markowitz (2015) indicated that a change in family structure, from a biological two-parent family to a single-parent family, is associated with increased behavioral problems. On the other hand, Hakim Shooshtray, Panaghy and Hajebi (2008) found no significant difference between two-parent and single-parent families in terms of the prevalence of behavioral problems. Given the contradictory findings available, comparison of single-parent and two-parent adolescents in terms of behavioral problems seems to be a significant gap in the research. Shek (2005) showed that the incidence of behavioral problems is so inversely related to the subjective quality of life that the adolescents with higher levels of subjective quality of life have expressed less behavioral problems.

Quality of life is another important factor in the study of single-parent children. It is defined by the World Health Organization (1995) as "individuals' perception of their position in life, in the context of the culture and value systems in which they live and in relation to their goals, expectations, standards and concerns". Accordingly, the quality of life is grouped into four physical, psychological, social and environmental domains in the WHOQOL-BREF instrument (Skevington, Lotfy, \& Oconnell, 2003). Depending on the life satisfaction of each individual, quality of life is different from the perspective of people living in different situations and is associated with on factors such as age, culture, gender, education, social status, social environment and disease (King \& Hines, 2003). In Frisch's Quality of Life theory (2006), quality of life is equivalent to life satisfaction, which is defined as "the individual's subjective assessment of the fulfillment of his/her needs, goals and aspirations". Some studies, however, have demonstrated the negative effects of divorce on children's quality of life (Eymann, Busanich, Liera, Cunto, \& Wahren, 2009; Orgilés \& Samper, 2011); and compared to the two-parent children, single-parent children have often been reported in some studies to exhibit more problems in physical (Scharte \& Bolte, 2013; Sauvola et al., 2000; Nunes-Costa, Lamella, \& Figueiredo, 2009), psychological (Shenoy, Lee, \& Trieu, 2016; Falana, Olatunji Bada, \& Ayodele, 2012); and social domains (Hatherington, M. Cox, \& R. Cox, 2010; and Falana, Olatunji Basa, \& Ayodele, 2012). 
Considering the issues described above, a comparison between the states of identity, quality of life and behavioral problems in single-parent and two-parent adolescents seem to be essential to address the research gaps. Identification of the factors related to single-parent status and the underlying differences in single-parent and two-parent adolescents can be helpful in creating suitable conditions for education. Therefore, this study attempts to examine this question: "Is there a significant difference in identity styles, quality of life and behavioral problems between single-parent and two-parent adolescents?".

\section{Research Methodology}

\subsection{Method}

The study employed a causal comparative research (ex post facto) design, in which the population was composed of all male and female high school students in the second semester of 2015-2016 school year in Bonab city. The sample consisted of the single-parent students who were identified by the screening method and selected using the convenience sampling method, including 59 female and 53 male students. The screening tests performed on the single-parent students were used to randomly select the same number of two-parent students from the same school and the same classroom (Both groups were thus matched in terms of important variables). Therefore, a total of 224 single-parent or two-parent students were studied (112 in each group).

\subsection{Procedure}

After preparing the required instruments (including Bennion and Adams' Objective Measure of Ego Identity Status (OMEIS-2), Youth Self-report Scale (YRS) and the World Health Organization's Quality of Life-BREF Questionnaire (WHOQOL-BREF)), the researcher personally attended the girls' schools to identify the single-parent adolescents with the help of school officials, once permission was obtained from Bonab's Department of Education. Then, the same number of two-parent students were randomly selected from the same school and classroom. After providing relevant explanations, we distributed the questionnaires, which after being completed, were collected from the students on the next day. Since the presence of the researcher in boys' schools was subjected to legal restrictions by the Department of Education, an education expert completed the above steps in boys' schools.

\subsection{Research Instruments}

The following questionnaires were used in this study:

i) Bennion and Adams' Objective Measure of Ego Identity Status (OMEIS-2): This questionnaire, developed based on Erikson's and Marcia's theory, measures the identity statuses in people aged 14 to 56 years. Performance of this questionnaire is collective. It includes 64 items and four subscales (diffused identity, foreclosed identity, moratorium and achieved identity). Cronbach's alpha was obtained for the subscales of moratorium (0.75), ideological achievement $(0.60)$, foreclosure $(0.80)$, and identity diffusion $(0.64)$. The results of a factor analysis by Bennion and Adams led us to the conclusion that identity diffusion and moratorium overlap, despite their distinct concept (Bennion \& Adams, 1986). Cronbach's alpha in this study was obtained as 0.62 for diffused identity, 0.79 for foreclosed identity, 0.69 for moratorium and 0.78 for achieved identity.

ii) WHOQOL-BREF Questionnaire: the World Health Organization's Quality of Life Questionnaire is a shortened form of the World Health Organization Quality of Life 100 Questionnaire, which examines the quality of life for four health-related domains (physical, psychological, social relationship and environmental domains). The scale contains 26 questions: the first and the second are related to the overall quality of life and overall health status, respectively, while the next 24 questions evaluate the quality of life in the four mentioned domains (The WHOQOL grope, 1995). To assess the reliability and validity of this questionnaire, we performed a study in Tehran, in which 1167 participants were divided into two groups with and without chronic diseases. Test-retest reliability for the subscales was obtained as follows: the test-retest reliability of this scale is above $70 \%$ in all domains and Cronbach's alpha in physical, psychological and environmental domains has an acceptable value (the latter is less than $70 \%$ in social relationships). Table 3 shows the internal consistency calculated using Cronbach's alpha (Nejat, Montazeri, Holakouee, Mohammadi, \& Majd Zadeh, 2006). Cronbach's alpha in this study was equal to $0.50,0.51,0.52$ and 0.80 for physical, psychological, social and environmental domains, respectively.

iii) Youth Self-Report Scale (YSR): The scale, developed by Achenbach, is a self-report scale for ages 11 to 18, consisting of Competencies and Symptoms sections. The Symptoms section of the questionnaire, containing 113 three-option items $(0=$ false, $1=$ somewhat or sometimes true and $2=$ completely or often true $)$ was completed in this study by the adolescents on the basis of their status during the six previous months. Total of the scores of 1 and 2 for these 113 questions reported as the overall behavior problems (Achenbach \& Rescorla, 2001). This 
questionnaire has been normalized by Minaei for Iranian society. The 8-factor structure of this scale was confirmed based on the results of a survey on the construct validity of this scale using the factor analysis in Iran. The convergent validity of the scale with the J-EPQ questionnaire and Rutter behavior problems Index was satisfactory. The validity of the YSR (using an approach based on the Achenbach system of empirically based assessment) was obtained for the boys and girls using Cronbach's alpha (0.89 and 0.94) and using the split-half method (0.84 and 0.87). The subscales of anxious/depressed, withdrawn/depressed, somatic complaints, social problems, thought problems, attention problems, rule-breaking behavior, aggressive behavior, and general problems had Cronbach's alpha reliability coefficient of $0.83,0.85,0.78,0.79,0.66,0.78,0.64,0.87$ and 0.79 , respectively, and split-half reliability coefficients of $0.77,0.71,0.68,0.86,0.67,0.87,0.69,0.86$ and 0.83 (Minaei, 2005). Cronbach's alpha in this study was also calculated for the subscales of anxious/depressed (0.78), withdrawn/depressed $(0.70)$, somatic complaints $(0.64)$, social problems $(0.72)$, thought problems $(0.69)$, attention problems $(0.63)$, rule-breaking behavior $(0.62)$, aggressive behavior $(0.79)$, other problems $(0.66)$ and general problems $(0.94)$.

\section{Results}

To determine the average performance of the single-parent and two-parent adolescents and the distribution of scores on each of the variables, the statistical data for both groups (the single-parent and two-parent adolescents) are presented in Table 1.

Table 1. Means and standard deviations of adolescents with single parent and two parent statuses

\begin{tabular}{|c|c|c|c|c|}
\hline & \multicolumn{2}{|c|}{ Single-parent adolescent } & \multicolumn{2}{|c|}{ two-parent adolescent } \\
\hline & mean & std. deviation & mean & std. deviation \\
\hline Age & 16.71 & 0.94 & 16.46 & 0.79 \\
\hline Quality of life & 58.60 & 12.63 & 56.61 & 11.96 \\
\hline Physical health domain & 17.98 & 5.37 & 16.88 & 5.22 \\
\hline Psychological domain & 7.59 & 1.85 & 7.34 & 1.88 \\
\hline Social relationship domain & 13.97 & 3.67 & 13.92 & 3.50 \\
\hline Environment domain & 18.87 & 4.13 & 18.26 & 3.61 \\
\hline Behavioral problems & 62.21 & 27.48 & 58.97 & 23.82 \\
\hline anxious/depressed & 8.13 & 4.96 & 6.75 & 4.13 \\
\hline withdrawn/depressed & 5.65 & 3.27 & 4.92 & 3.20 \\
\hline somatic complaints & 4.44 & 4.35 & 5.03 & 4.13 \\
\hline social problems & 5.28 & 3.62 & 4.72 & 3.50 \\
\hline thought problems & 7.88 & 4.42 & 7.85 & 3.86 \\
\hline attention problems & 6.69 & 3.45 & 6.82 & 3.15 \\
\hline rule-breaking behavior & 5.94 & 3.73 & 5.59 & 2.84 \\
\hline aggressive behavior & 8.27 & 5.06 & 7.67 & 4.99 \\
\hline other behavioral problems & 11.68 & 4.44 & 12.29 & 4.16 \\
\hline Achieved identity & 45.72 & 9.95 & 42.37 & 7.82 \\
\hline Identity diffusion & 51.97 & 9.27 & 52.74 & 8.71 \\
\hline foreclosure & 46.34 & 8.52 & 49.84 & 10.92 \\
\hline moratorium & 59.99 & 9.05 & 61.61 & 8.62 \\
\hline
\end{tabular}

As shown in the table, the quality of life and behavior problems have an average of 58.60 and 62.21 in the single-parent adolescents, respectively. Moratorium identity (59.99) and achieved identity (45.72) have the highest and lowest averages among the different types of identity, respectively. In addition, the quality of life and behavior problems have an average of 56.61 and 58.97 in the two-parent adolescents, respectively. 
Hypothesis 1) The quality of life differs in single-parent and two-parent adolescents.

In order to examine differences in quality of life between the two groups, an independent samples t-test was conducted (Table 2).

Table 2. Results of independent t-test for quality of life in adolescents from single parent and two parent families

\begin{tabular}{lcccccc}
\hline & & \multicolumn{2}{c}{$\begin{array}{c}\text { Levene's test for equality of } \\
\text { variances }\end{array}$} & \multicolumn{3}{c}{ t-test for equality of means } \\
\cline { 3 - 8 } & & $\mathrm{F}$ & $\mathrm{sig}$ & $\mathrm{T}$ & $\mathrm{df}$ & $\mathrm{sig}$ \\
\hline Quality of life & Equal variances assumed & 0.093 & 0.761 & 1.21 & 222 & 0.226 \\
& Equal variances not assumed & & & 1.21 & 221.346 & 0.226 \\
\hline
\end{tabular}

Given a violation of Levene's test for homogeneity of variances, $F(1,222)=0.093, p=0.76$, a t-test assuming homogeneous variances was calculated. The average score on the quality of life in single-parent adolescents (SD $=12.63$ and $\mathrm{M}=58.60)$ was compared to that of the two-parent adolescents $(\mathrm{SD}=11.96$ and $\mathrm{M}=56.61)$. There was no statistically significant difference between the two groups $(\mathrm{p}<0.226$ and $\mathrm{t}(222)=1.21)$, and thus the quality of life did not differ in single-parent and two-parent adolescents.

To examine the four subscales of quality of life (given that the distribution of data is normal in all environmental, social, psychological and physical health domains), multivariate analysis of variance was used by taking other assumptions of MANOVA into account.

Table 3. Results of multivariate analysis of variance (MANOVA) for quality of life domains in adolescents from single parent and two parent families

\begin{tabular}{cccccc}
\hline Effect & Value & F & Hypothesis df & Error of & sig \\
\hline Pillai's Trace & 0.017 & $0.970^{b}$ & 4.00 & 219.00 & 0.425 \\
Willis' Lambda & 0.983 & $0.970^{b}$ & 4.00 & 219.00 & 0.425 \\
Hoteling's Trace & 0.018 & $0.970^{b}$ & 4.00 & 219.00 & 0.425 \\
Roy's Largest Root & 0.018 & $0.970^{b}$ & 4.00 & 219.00 & 0.425 \\
\hline
\end{tabular}

The results of Wilks Lambda test $(\mathrm{p}<0.425$ and $\mathrm{F}(4$ and 219$)=0.97)$ show no statistically significant difference between the two groups in the above subscales of quality of life (Table 3 ).

Table 4. Results of multivariate analysis of variance (MANOVA) for quality of life domains in adolescents from single parent and two parent families

\begin{tabular}{cccccc}
\hline & Sum of squares & df & Mean square & F & sig \\
\hline Physical health domain & 20.67 & 1 & 20.67 & 1.37 & 0.243 \\
Psychological domain & 0.13 & 1 & 0.13 & 0.011 & 0.918 \\
Social relationship domain & 3.66 & 1 & 3.66 & 1.04 & 0.307 \\
Environmental domain & 68.86 & 1 & 68.86 & 2.45 & 0.119 \\
\hline
\end{tabular}

Research Question 1) Are the identity styles different in single-parent and two-parent adolescents?

In order to answer the research question, the multivariate analysis of variance was used, given the normal distribution of data and other assumptions of variance analysis. 
Table 5. Results of multivariate analysis of variance (MANOVA) for identity styles in adolescents from single parent and two parent families

\begin{tabular}{cccccc}
\hline effect & Value & F & Hypothesis df & Error df & sig \\
\hline Pillai's Trace & 0.26 & $19.58^{b}$ & 4.00 & 219.00 & 0.00 \\
Willis' Lambda & 0.73 & $19.58^{b}$ & 4.00 & 219.00 & 0.00 \\
Hoteling's Trace & 0.35 & $19.58^{b}$ & 4.00 & 219.00 & 0.00 \\
Roy's Largest Root & 0.35 & $19.58^{b}$ & 4.00 & 219.00 & 0.00 \\
\hline
\end{tabular}

The results of Wilks Lambda test $(0.000>\mathrm{P}$ and $\mathrm{F}(4$ and 219$)=6.075)$ show that a significant difference can be found between the two groups in at least one of the statuses of identity (achieved identity, moratorium, foreclosed identity and diffused identity) (Table 5).

Table 6. Results of multivariate analysis of variance (MANOVA) for identity styles in adolescents from single parents and two parent families

\begin{tabular}{cccccc}
\hline & Sum of squares & df & Mean square & F & sig \\
\hline Achieved identity & 638.86 & 1 & 638.86 & 7.91 & 0.005 \\
Identity diffusion & 34.43 & 1 & 34.43 & 0.42 & 0.517 \\
foreclosure & 698.62 & 1 & 698.62 & 7.19 & 0.008 \\
moratorium & 149.57 & 1 & 149.57 & 1.89 & 0.170 \\
\hline
\end{tabular}

As illustrated in Table 6, there is a significant difference between two groups in achieved identity $(\mathrm{p}<0.005$ and $\mathrm{F}(1,222)=7.91)$ and foreclosed identity $(\mathrm{p}<0.008$ and $\mathrm{F}(1,222)=7.19)$. According to the descriptive statistics for both groups, the single-parent adolescents have a better status in achieved identity (SD $=9.95$ and $\mathrm{M}=45.72)$ than the two-parent adolescents $(\mathrm{SD}=7.88$ and $\mathrm{M}=42.34)$, and the two-parent adolescents have also gained higher scores on foreclosed identity $(\mathrm{SD}=11.02$ and $\mathrm{M}=49.87)$ than the single-parent adolescents $(\mathrm{SD}=8.52$ and $\mathrm{M}=46.34)$. Thus, the single-parent and two-parent adolescents have mostly on achieved identity and foreclosed identity, respectively.

Research Question 2) Are behavioral problems different in single-parent and two-parent adolescents?

In order to examine differences in behavioral problems between two groups, an independent samples t-test was conducted (Table 7).

Table 7. Results of independent t-test for behavioral problems in adolescent from single parents and two parent families

\begin{tabular}{lccccc}
\hline & \multicolumn{2}{c}{$\begin{array}{c}\text { Levene's test for equality of } \\
\text { variances }\end{array}$} & \multicolumn{3}{c}{ t-test for equality of means } \\
\cline { 2 - 7 } & $\mathrm{F}$ & $\mathrm{sig}$ & $\mathrm{T}$ & $\mathrm{df}$ & $\mathrm{sig}$ \\
\hline Behavioral problems Equal variances assumed & 3.592 & 0.59 & 0.944 & 222 & 0.346 \\
Equal variances not assumed & & & 0.944 & 217.622 & 0.346 \\
\hline
\end{tabular}

Given a violation of Levene's test for homogeneity of variances, $F(1,222)=3.59, \mathrm{p}=0.59$, a t-test assuming homogeneous variances was calculated. The average score on behavior problems in the single-parent adolescents $(\mathrm{SD}=27.48$ and $\mathrm{M}=62.21$ ) was compared, using the independent groups t-test, with that in the two-parent adolescents $(\mathrm{SD}=23.82$ and $\mathrm{M}=58.97)$. The comparison showed no significant difference between the single-parent and two-parent adolescents $(\mathrm{p}<0.346$ and $\mathrm{t}(222)=0.944)$. 
To examine the nine subscales of behavior problems (anxious/depressed, withdrawn/depressed, somatic complaints, social problems, thought problems, attention problems, delinquent behavior, aggressive behavior, and other behavior problems), we use the multivariate analysis of variance.

Table 8. Results of multivariate analysis of variance (MANOVA) for behavioral problems domains in adolescents from single parent and two parent families

\begin{tabular}{cccccc}
\hline effect & Value & F & Hypothesis df & Error df & sig \\
\hline Pillai's Trace & 0.01 & $1.99^{b}$ & 9.00 & 214.00 & 0.041 \\
Willis' Lambda & 0.92 & $1.99^{b}$ & 9.00 & 214.00 & 0.041 \\
Hoteling's Trace & 0.08 & $1.99^{b}$ & 9.00 & 214.00 & 0.041 \\
Roy's Largest Root & 0.08 & $1.99^{b}$ & 9.00 & 214.00 & 0.041 \\
\hline
\end{tabular}

The results of Wilks Lambda test $(p<0.041$ and F $(1.99$ and 9$)=0.923)$ show a significant difference between the two groups in at least one of the subscales of behavior problems (anxious/depressed, withdrawn/depressed, somatic complaints, social problems, thought problems, attention problems, delinquent behavior, aggressive behavior, and other behavior problems) (Table 8).

Table 9. Results of multivariate analysis of variance (MANOVA) for behavioral problems domains in adolescents from single parent and two parent families

\begin{tabular}{cccccc}
\hline & Sum of squares & df & Mean square & F & sig \\
\hline Anxious/depressed & 106.76 & 1 & 106.76 & 5.11 & 0.025 \\
Withdrawn/depressed & 29.41 & 1 & 29.41 & 2.79 & 0.096 \\
Somatic complaints & 19.37 & 1 & 19.37 & 1.07 & 0.301 \\
Social problems & 17.67 & 1 & 17.67 & 1.39 & 0.239 \\
Thought problems & 0.052 & 1 & 0.052 & 0.003 & 0.956 \\
Attention problems & 0.87 & 1 & 0.87 & 0.08 & 0.778 \\
Rule-breaking behavior & 6.91 & 1 & 6.91 & 0.62 & 0.429 \\
Aggressive behavior & 20.67 & 1 & 20.67 & 0.81 & 0.397 \\
Other problems & 20.81 & 1 & 20.81 & 1.12 & 0.291 \\
\hline
\end{tabular}

As illustrated in Table 9, a significant difference can be found between the two groups regarding the subscale of anxious/depressed $(\mathrm{p}<0.025$ and $\mathrm{F}(1,222)=5.11)$. The single-parent adolescents $(\mathrm{SD}=4.96$ and $\mathrm{M}=8.13)$ have gained a higher score on anxious/depressed subscale than the two-parent adolescents $(\mathrm{SD}=4.13$ and $\mathrm{M}=$ 6.75). Thus, the single-parent adolescents show more anxious/depressed behaviors than the two-parent adolescents.

\section{Discussion}

The study aimed to compare identity styles, behavioral problems and quality of life in single-parent and two-parent adolescents.

The results of this study showed no significant difference between the two groups, either in total score on the quality of life or any of its subscales. Ventegodt, Merrick, and Jorgen Anderson (2003) have suggested that, "the symmetry and concord can come about in two ways: either we try to change the external world so that it matches our dreams or we give up our dreams because they are unrealistic, and adapt them to the world as it is, thus creating concord between the external world and our dreams. Both approaches generate the same satisfaction." The results of this study show that the single-parent adolescents have been able to make use of the two ways just as good as the two-parent adolescents to achieve life satisfaction and quality of life. Tallmann's (1994) study on the quality of life and well-being in single-parent families identified the key factors damaging single-parent families, such as cultural norms and values, the health of family members, social factors, social support networks, 
social institutions, financial situation, and policies governing the society and education system. However, there is much reason to believe that the quality of life does not differ in the single-parent adolescents (despite their specific conditions) versus the two-parent adolescents: (1) the increasing employment rate of women, which affects the financial situation of single-parent families; (2) the cultural and religious norms and values governing the country, which place considerable emphasis on the treatment of orphans and the injured in the society; and (3) the support these families receive from close and distant relatives, acquaintances, and governmental and non-governmental organizations. Social support, as reported by Coyn (2003), has a positive effect in increasing the perception of single parent (mother) families of their quality of life.

The results of this study showed a higher degree of achieved identity among the single-parent adolescents. The results of this study are inconsistent with those of Slutsky et al. (2005) who found that the identity development is affected by the quality of parent-child relationship in the adolescents who suffer from the absence of father. The study results are inconsistent with those of Imbimbo (1995) who showed that identity styles do not differ in single-parent and two-parent adolescents. To explain the findings, we first examine the results of Strenger (2004). He examined the young people who had grown up without a father and found that in order to form their identity they require less guidance from earlier generations and rely less on cultural continuity with their parents. They seek to find an identity by creating their own lifestyle and assigning previously non-existent roles and social functions. From another angle, the formation of identity can be seen to be affected by interpersonal factors. Therefore, the formation of his or her identity will be successful as much as the individual assimilates with the people whom he/she respects and listens to (Adams, Ryan, \& Keating, 2000). The impact the absence of one parent has on children's development seems to depend on the extent to which other adults or siblings substitute for the absent parent. However, the single-parent adolescents' achievement of achieved identity is affected by the support received from relatives, family members and governmental and non-governmental organizations because, as Smits et al. (2008) reported, a normative identity style (equivalent to the status of achieved identity) can be predictable from the social support that is provided to single-parent families benefit, due to religious atmosphere as well as the cultural trends prevailing in our society. All the above factors can help single-parent adolescents to achieve a successful identity.

As mentioned earlier, the two-parent adolescents had mostly foreclosed identity. Given that the adolescents with a foreclosed identity do not experience the identity crisis (Santrak, 2003), the findings of this study are consistent with those of Parhizgar (2002), who found that those students who lack an identity crisis, have a better relationship with their parents; for the reason that the two-parent adolescents are likely to have better parent-child relationships than the single-parent adolescents (because they live with both parents). These findings are inconsistent with those of Imbimbo (1995) who reported that identity styles are not different in single-parent or two-parent students. Finally, as stated by Marcia (1966), people with a foreclosed identity or moratorium have committed themselves to some values and objectives, without exploring the options. They have accepted a ready-made identity selected for them by those in power (usually parents and sometimes teachers, religious leaders or romantic mistresses). According to Marcia, the presence of both biological parents can more lead the two-parent adolescents than single parent adolescents to achieve a foreclosed identity.

The results of this study demonstrated that the single-parent adolescents showed more anxiety/depression than the two-parent adolescents. The results are consistent with the findings of Karimi, Bolgari and Asgharnejad (2007), Ryan, Claessens and Markowitz (2015); Mageina (1997) and Liu, Guo, Okawa, Zhai, Li, Uchiyama, Neiderhiser and Coretta (2000), but inconsistent with those of Hakim Shooshtray, Hajebi, Panaghy and Abedi (2008). In Coleman's theory (1980), any of the adolescence problems reach the maximum (or peak) stress in a particular chronological age (which is different and unchanged both in terms of people and various problems of adolescence), and the adolescents' adjustments are faced with problems when the peak age of stress coincides with the occurrence of certain problems. In such a situation, behavior problems become more visible to them and the coincidence of these stresses with the problems (and stresses) caused by single-parent status leads to more behavior problems in single-parent adolescents in comparison with two-parent adolescents.

Some limitations of this study are the inability of the researcher to identify all single-parent adolescents in Bonab City, the restriction of the population to adolescents of Bonab City, and the limited resources to obtain information (i.e., the students themselves). To train on how to deal with the single-parent adolescents, the results of this study suggest that (i) the single-parent families should be covered to better take advantage of counseling and psychology services; (ii) the Department of Education should identify single-parent students and provide educational and counseling services to this vulnerable group; and (iii) training sessions should be organized by the cultural and educational centers for the heads of single-parent families. Regarding research proposals, the single-parent children who are not studying are suggested to be used as subjects in future studies. In addition, 
since this study only focused on the adolescents, the above variables are suggested to be considered for children and young people. Furthermore, in collecting data instead of relying on quantitative methods, qualitative methods (such as interviews and observation) should also be used in studies.

\section{References}

Adams, G. R., Ryan, B. A., \& Keating, L. (2000). Family Relationships, Academic Environments, and Psychosocial Development during the University Experience: A longitudinal Investigation. Journal of Adolescent Research, 15, 99-122. https://doi.org/10.1177/0743558400151006

Alami, A., Khosravan, S., Sadegh mogadam, L., Pakravan, F., \& Hosseini, F. (2014). Adolescent' self-esteem in single and two-parent families. International journal of community based nursing and midwifery.

Achenbach, T. M., \& Rescorla, L. (2001). Manual for the ASHBA school-age forms \& profile: Burlington, VT: University of Vermont, research center of Children, Youth, \& Families.

Bennion, L. D., \& Adams, G. R. (1986). A revision of the extended version of the objective measure of ego identity status: An identity instrument for use with late adolescents. Journal Adolesc. Res., 1, 183-198. https://doi.org/10.1177/074355488612005

Burt, K. B., \& Paysnick, A. A. (2014). Identity, stress, and behavioral and emotional problems in undergraduates: Evidence for interaction effects. Journal of College Student Development, 55(4), 384-468. https://doi.org/10.1353/csd.2014.0036

Colman, J. C. (1980). The nature or adolescence. London, n. y. Methuen.

Coyne, G. (2003). An investigation of coping skills and quality of life among single sole supporting mothers. International Journal of Anthropology, 18, 127. https://doi.org/10.1007/BF02447541

Eymann, A., Busanich, J., Liera, J., De Cunto, C., \& Wahren, C. (2009). Impact of divorce on the quality of life in school-age children. Journal Pediatr, 85(6), 546-552. https://doi.org/10.2223/JPED.1958

Faber, A. J., Edwards, A. E., Bauer, K. S., \& Wetchler, J. L. (2006). Family structure: Its effects on adolescent attachment and identity formation. American Journal of Family Therapy, 31(4), 243-255. https://doi.org/10.1080/01926180390201945

Falana, B. A., Olatunji bada, F., \& Ayodele, C. J. (2012). Single-parent family structure, psychological, social and cognitive development of children in Ekiti State. Journal of Educational and Developmental Psychology, 2(2). https://doi.org/10.5539/jedp.v2n2p158

Frisch, M. B. (2006). Quality of life therapy. Applying a life satisfaction approach to positive psychology and cognitive therapy.

Gladding, S. T. (2011). Family therapy: History, theory, and practice (5th ed.).

Gobari-Bonab, B., Parand, A., Khanzade Firoozjah, A., Movaleli, G., \& Nemati, S. H. (2008). The prevalence of behavioral problems in primary school children in Tehran. Research on Exceptional Children, 8(3). In Persian

Greenberg, J. S. (2002). Comprehensive Stress Management (7th ed.). New York: McGraw-Hill Companies.

Hakim Shooshtray, M., Panaghy, L., Hajebi, A., \& Abedi Sh. (2008). Emotional and behavioral problems of single parent vs. two parent children: Imam Khomeini Charity. Journal of Tehran Univ Med, 66(3), 196-202. In Persian

Hotherington, E. M., Cox, M., \& Cox, R. (2010). Play and social interaction in children following divorce. Journal of Social Issues, 35(4), 26-49. https://doi.org/10.1111/j.1540-4560.1979.tb00812.x

Imbimbo, P. V. (1995). Sex differences in the identity formation of college students from divorced families. Journal of Youth and Adolescence, 24(6), 745-761. https://doi.org/10.1007/BF01536955

Jiumpanyarach, W. (2011). Single-parent families in Bangkok, Thailand: Factors affecting children living in single-parent families (Theses and dissertation). Sociology university of Kentucky.

Karami, K., Bolhari, J., \& Asgharnejad, A. (2007). Effect of father loos on behavioral disorders in primary school children. Iranian Journal of Psychiatry and Clinical Psychology, 12(4).

King, C. R., \& Hinds, P. S. (2003). Quality of life: From nursing and patient perspectives: Theory, Reserch, Practice. Jones \& baetlett learning-medical.

Landucci, N. (2008). Impact of divorce on children: What school counselors need to know. 
Liu, X., Guo, C., Okawa, M., Zhai, J., Li, Y., Uchiyama, M., ... Kurita, H. (2000). Behavioral and emotional problems in Chinese children of divorced parents. Journal of the American Academy of Child \& Adolescent Psychiatry, 39(7), 896-903. https://doi.org/10.1097/00004583-200007000-00019

Marcia, J. E. (1966). Development and validation of ego-identity status. Journal of Personality and Social Psychology, 3(5), 551. https://doi.org/10.1037/h0023281

Maginnis, R. L. (n.d.). Single-parent families cause juvenile crime. Juvenile Crime, 62-66.

Minaei, A. (2005). Guidance booklet of school age forms. Evaluation system based on experience of Achenbach (ASEBA). Adaption and exceptional children. (In Persian)

Mishra, P., \& Kiran, U. V. (2013). Impact of Ordinal Position on self-concept among Adolescents. Advanced Research Journal of Social Science (An International Referred Research Journal), 4(1), 35-38.

Nejat, S., Montazeri, A., Holakouee, N., Mohammadi, K., \& Majd Zadeh, S. (2006). Standardization of life qualify questionnaire of hygiene universal organization. Translation and psychometrics of Iranian types. Journal of Hygiene College and hygiene scholarisms institution, 4(4), 1-12. (In Persian)

Nunes-Costa, R. A., Lamela, D. J., \& Figueiredo, B. F. (2009). Psychosocial adjustment and physical health in children of divorce. Jornal de pediatria, 85(5). https://doi.org/10.2223/JPED.1925

Para, E. A. (2008). The role of social support in identity formation: A literature review. Graduate Journal of Counseling, Psychology, 1(1).

Parhizgar, A. (2002). The comparison of quality of child-parent relationship of students with identity crisis of girlish high schools of Kazeroon city (Thesis of Master of Arts). Techer training university. (In Persian)

Ryan, R. M., Claessens, A., \& Markowitz, A. J. (2015). Association between family structure change and child behavior problem: The moderating effect of family income. Child Development, 86(1), 112-127. https://doi.org/10.1111/cdev.12283

Santrock, J. W. (2003). Psychology. Published by McGraw-Hill, Americas, New York.

Samuelsson, M. (1997). Social network of children in signle parent families, differences according to sex, age, socioeconomic.status and housing type and their assocration with behaviour disturbances. Nordic Journal of Psychiatry, 125-140.

Sauvola, A., Mäkikyrö, T., Jokelainen, J., Joukamaa, M., Järvelin, M., \& Isohanni, M. (2000). Single-parent family background and physical illness in adulthood: A follow-up study of the northern Finland 1966 birth cohort. Public, Environmental \& Occupational Health, 28(2), 95-101. https://doi.org/10.1177/140349480002800204

Scharte, M., \& Bolte, G. (2013). Increased health risks of children with single mother: The Impact of socio-economic and environmental factors. Ear $J$ Public Health, 23(3), 469-475. https://doi.org/10.1093/eurpub/cks062

Schwartz, S., \& Pantin, H. (2005). Family functioning, identity, and problem behavior in Hispanic immigrant early adolescents. Journal Early Adobes, 25(4), 392-420. https://doi.org/10.1177/0272431605279843

Seifollah poor-bonab, M., \& Keshavarzy-arshady, F. (2015). Behavioral disorder in adolescent girls with single parent. Journal of Applied Environment and Biological Sciences, 5(11s), 798-802.

Shek, D. T. (2005). Economic stress, emotional quality of life, and problem behavior in chinese adolescents with and without economic disadvantage. Social Indicator Research, 71(1), 363-383. https://doi.org/10.1007/1-4020-3602-7_12

Shenoy, D. P., Lee, C., \& Trieu, S. L. (2016). The mental health status of single-parent community college students in California. Journal of American College Health, 64(2). https://doi.org/10.1080/07448481.2015.1057147

Singh, A., \& Kiran, U. K. (2012). Effect of single parent family on child delinquency. International Journal of Science and Research.

Skevington, S. M., Lotfy, M., \& Oconnell, K. A. (2003). The world health organization WHOQOL-BREF quality of life assessment psychometric properties and results of the international field trial. A report from WHOQOL group. 
Škraban, O. P. (2008). Researching the Identity Development of Individuals within the Family System. Socialna Pedagogika, 12(5), 531-546.

Slobodskay, H. R. (2015). Behavioral problems, effects of parenting and family structure on. In International Encyclopedia of the Social Behavioral Sciences (2nd ed., pp. 470-476). https://doi.org/10.1016/B978-0-08-097086-8.23047-X

Slutsky, J., Javadi, V., Freeman, T., Persaud, S., Steele, M., Steele, H., ... Srivastava, S. K. (2005). Applied and community psychology. Trends and directions.

Smits, I., Soenens, B., Luyckx, K., Duriez, B., Berzonsky, M., \& Goossens, L. (2008). Perceived parenting dimensions and identity styles: Exploring the socialization of adolescents' processing of identity-relevant information. Journal of Adolescent, 31(2), 151-164. https://doi.org/10.1016/j.adolescence.2007.08.007

Strenger, C. (2004). Nobrow identity formation in a fatherless generation. Psychoanalytic Psychology, 21(4), 499-515. https://doi.org/10.1037/0736-9735.21.4.499

Tallman, M. I. (1994). Quality of life and well-being of single parent families. Marriag \& Family Review, 20(3-4), 513-532. https://doi.org/10.1300/J002v20n03_11

The WHOQOL Groop. (1995). The world health organization quality of life assessment. Position paper from the world health organization.

Usakli, H. (2013). Comparison of single and two parents children in terms of behavioral tendencies. International Journal of Humanities and Social Science, 3(8).

Vaičiulienè, A. (1999). Adolescent identity development in parental divorce experiences family (pp. 32-40). VU Faculty of Philosophy Psychology.

Vantegodt, S., Merrick, J., \& Andersen, N. J. (2003). Quality of life theory the IQOL theory: An integrative theory of the global quality of life concept. The Scientific World Journal, 3, 1030-1040. https://doi.org/10.1100/tsw.2003.82

\section{Note}

Note 1. According to the Civil Registration, the divorce rate in 1390 increased to more than twice that in 1375.

\section{Copyrights}

Copyright for this article is retained by the author(s), with first publication rights granted to the journal.

This is an open-access article distributed under the terms and conditions of the Creative Commons Attribution license (http://creativecommons.org/licenses/by/4.0/). 